\title{
CONTABILIZAÇÃO DAS ONDAS DE FRIO EM CURITIBA - PARANÁ
}

\author{
Rafael Brito Silveira ${ }^{(a)}$, Geisa Silveira da Rocha ${ }^{(b)}$, Maikon Passos Amilton Alves ${ }^{(c)}$ \\ (a) Departamento de Geociências/LabClima, PPGG, UFSC, rafaelbsilveirageo@gmail.com \\ (b) Departamento de Geografia/LaboClima, PPGeografia, UFPR, geisa_sr@ hotmail.com \\ (c) Departamento de Geociências/LabClima, PPGG, UFSC, maiconpassos@gmail.com
}

Eixo: Climatologia em diferentes níveis escalares: mudanças e variabilidades

\begin{abstract}
Resumo
Esta pesquisa analisa a ocorrência das ondas de frio (OdF) anuais e mensais no município de Curitiba entre os anos de 1961 e 2016, utilizando-se do método de Vavrus et al. (2006), baseando-se em dados de temperatura média diária do ar observados. Foram encontradas $150 \mathrm{OdF}$ em toda série histórica, com destaque para os meses de inverno, seguidos pelos meses das estações de transição. Observou-se ainda que as OdF estão passando por uma tendência de diminuição nos últimos anos. É possível afirmar que Curitiba possui limiares rigorosos para se classificar uma onda, demonstrando que o local passa por episódios de frio intenso. Através da interpolação da OdF mais intensa da série histórica em Curitiba, baseando-se também em estações vizinhas, verificou-se que a mesma conteve valores de temperatura distintos no território, com temperaturas mais baixas no sentido oeste e noroeste.
\end{abstract}

Palavras chave: temperatura média; frio extremo; onda de frio; Região Sul.

\section{Introdução}

A Região Sul, de forma geral, apresenta os menores registros de temperaturas do ar quando comparada com outras regiões brasileiras, especialmente por estar entre latitudes mais altas. Conforme Nimer (1979), as incursões de ar frio na região sul do Brasil quando atuantes reduzem ainda mais as temperaturas, por vezes com valores próximos de $0^{\circ} \mathrm{C}$ e até negativos. Os fatores que possuem maior interação com os sistemas atmosféricos são: a continentalidade, o relevo, a altitude e a maritimidade, portanto, são muito influentes (MONTEIRO; MENDONÇA, 2014, p.5). Os anticiclones polares são os responsáveis por trazerem para a região sul do Brasil o ar frio e o tempo estável, ocorrendo nestes períodos a predominância do céu claro, o que acaba diminuindo ainda mais a temperatura devido a perda de radiação noturna. Neste período o desconforto térmico pode ser ressaltante com a presença de ventos (NIMER, 1979). Com relação à Região Sul e ao Paraná, de forma geral, no inverno é que se identificam as menores médias de temperatura do ar, devido aos fatores climáticos dinâmicos que atuam sobre a região neste período como a Frente Polar Atlântica (FPa) e a Massa Polar Atlântica (MPa) (VANHONI; MENDONÇA, 2008).

Curitiba, capital do estado do Paraná (Figura 1), é a cidade mais populosa da Região Sul do Brasil, com uma população no Censo de 2010 de 1.751 .907 habitantes, estima-se que em 2016 a população já fosse de 


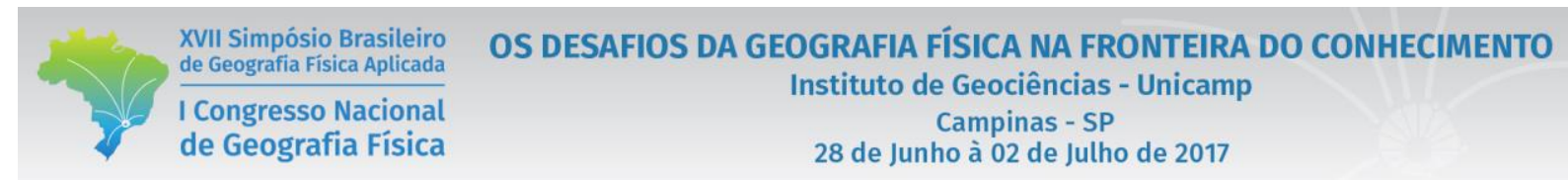

1.893.997, distribuídas em uma área territorial de 435,036 km² (IBGE, 2017). Conforme a classificação de Köppen-Geiger, o clima de Curitiba é predominantemente mesotérmico com verões frescos (Cfb), com invernos tipicamente secos. $\mathrm{O}$ mês mais quente é fevereiro, apresentando temperatura média de $22^{\circ} \mathrm{C}$ e junho é o mês mais frio, com temperatura media de $18^{\circ} \mathrm{C}$ podendo atingir até $-5^{\circ} \mathrm{C}$ (DANNI-OLIVEIRA, 1999). O inverno em Curitiba se estende de junho a agosto e destaca-se pela característica de clima tropical de altitude, que para Mendonça e Danni-Oliveira (2007) apresenta temperaturas muito baixas se comparado os padrões tropicais do Brasil, assim, com relação às condições térmicas, Curitiba é a capital mais fria do país.

Figura 1 - Localização de Curitiba e municípios em que estão as estações meteorológicas utilizadas no estudo.

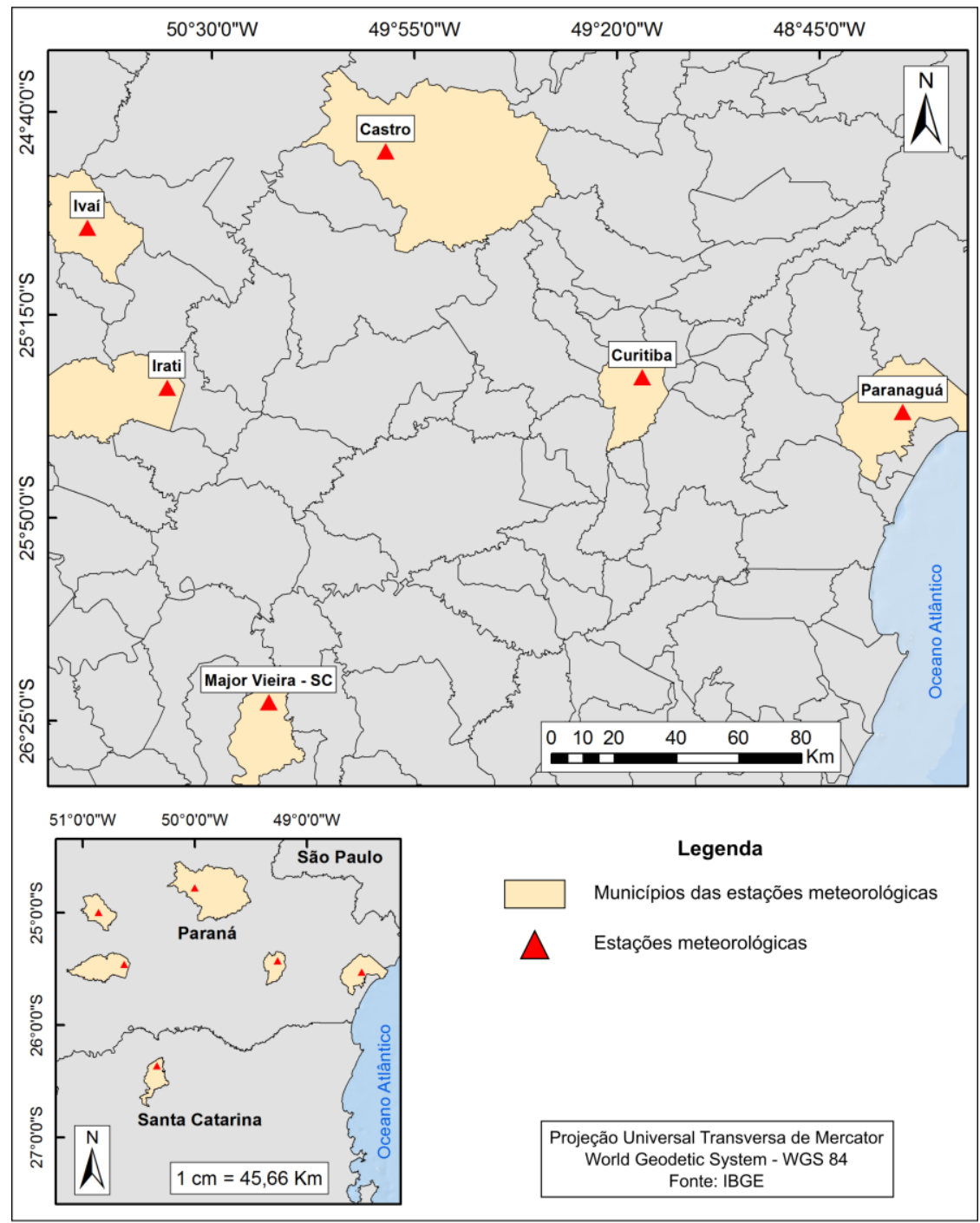

Destaca-se que enquanto a maioria das cidades brasileiras apresenta desconforto pelo calor, para Curitiba deve-se levar em consideração também o desconforto térmico por frio. Um estudo realizado por Rossi et 
al. (2012) definiu faixas de conforto e desconforto térmico para Curitiba com base no índice UTC (Universal Thermal Climate Index), as análises de sensação térmica mostraram que a faixa de desconforto térmico ao frio compreende temperatura do ar menor que $15^{\circ} \mathrm{C}$. Deste modo, no período em que as ondas de frio que atingem a capital paranaense a população em geral sente estresse térmico, uma vez que estes eventos apresentam, por vezes, temperaturas próximas a $0^{\circ} \mathrm{C}$, a exemplo de julho de 1972 quando ocorreu a onda de frio com maior intensidade (do dia 8 ao 11), em que a temperatura média do ar registrada no período de quatro dias foi de $3,3^{\circ} \mathrm{C}$. Para o Ministério da Integração Nacional do Brasil o frio extremo é considerado um desastre natural, afetando grupos vulneráveis como: idosos, enfermos e crianças, sobretudo quando pertencentes às populações de baixa de renda, podendo causar desde doenças até a morte (CASTRO et al., 2003).

Neste sentido, conforme supracitado justifica-se importante analisar também os impactos gerados por conta das ondas de frio nos municípios brasileiros, mesmo que o atual contexto das pesquisas climatológicas aponte para uma situação de aquecimento do planeta (IPCC, 2013), devido ao fato de que eventos extremos de frio ocorrerão em maior quantidade e estes são potencializadores e/ou desencadeadores de enfermidades e até óbitos. Para as populações mais carentes, o frio ao atingi-las, pode significar problemas para a saúde, incluindo, por exemplo, problemas respiratórios e cardiovasculares, além dos possíveis problemas para a agricultura em locais com tal vocação (CARSON et al., 2006). Por conta disto, o objetivo central da presente pesquisa foi identificar e contabilizar a ocorrência das OdF na capital paranaense, podendo verificar a distribuição dos eventos ao longo dos anos e dos meses entre os anos de 1961 e 2016.

\section{Materiais e Métodos}

Muitas são as técnicas para se classificar uma onda de frio, especialmente pelo frio ser algo subjetivo, não há unanimidade em um só conceito. Alguns autores baseiam-se nos sistemas atmosféricos ocorrentes; outros, além disso, tratam a respeito da duração da onda para classificá-la (TITARELLI, 1972; SARTORI, 2003; ESCOBAR, 2007; COSTA et al., 2007; FIRPO, 2008; MENDONÇA, ROMERO; 2012, p.187). Entretanto, nesta pesquisa utilizou-se o método de Vavrus et al. (2006), que considera como onda de frio o evento no qual a temperatura média diária do ar na superfície esta pelo menos duas vezes o desvio padrão abaixo do valor da média durante dois dias consecutivos ou mais. O desvio padrão (S) é o valor médio dos 365 desvios padrões diário de temperatura do ar. Sendo assim, é classificado como dia frio, aquele dia que registrar a temperatura média do ar abaixo ou igual ao limiar identificado para sua data e; para ser 
classificada como onda de frio é necessário que isso ocorra por dois dias consecutivos ou mais. Silveira (2016, p.65,66) demonstra a utilização deste método através de uma equação.

Os dados diários de temperatura do ar utilizados para identificar as ondas de frio foram os disponibilizados pelo Banco de Dados Meteorológicos para Ensino e Pesquisa (BDMEP) do Instituto Nacional de Meteorologia (INMET). Tais dados foram tabulados diariamente no programa Excel ${ }^{\circledR} 2010$ para os anos de 1961 a 2016, porém, os anos de 1979, 1980, 1981, 1984, 1985 e 2001, foram exluídos, pois apresentavam muitas falhas, totalizando então 50 anos de análise. Os dados diários que apresentaram falhas foram preenchidos através do método de ponderação regional. Este método geralmente é utilizado para preenchimento de séries mensais ou anuais, contudo, pode ser aplicado também para séries diárias, desde que esta ponderação seja feita com base em pelo menos três postos vizinhos que tenham 10 ou mais anos de registros (HORIKOSHI, FISH; 2007). Para a ponderação no caso desta pesquisa utilizou-se cinco estações meteorológicas, além da estação de Curitiba (Quadro I). A interpolação realizada para a OdF de julho de 1972 (exemplo apresentado posteriormente) também foi baseada na mesma técnica de preenchimento de falhas e nas mesmas estações meteorológicas.

Quadro I - Estações meteorológicas* utilizadas na pesquisa.

\begin{tabular}{|l|r|c|c|c|}
\hline \multicolumn{1}{|c|}{ Local } & Altitude da estação (m) & Código OMM & Long. & Lat. \\
\hline Curitiba & 923,5 & 83842 & -49.260 .000 & -25.430 .000 \\
\hline Paranaguá & 4,5 & 83844 & -48.510 .000 & -25.530 .000 \\
\hline Castro & 1008,8 & 83813 & -50.000 .000 & -24.780 .000 \\
\hline Major Vieira - SC & 765 & 86942 & -50.337 .222 & -26.365 .000 \\
\hline Ivaí & 808 & 83811 & -50.860 .000 & -25.000 .000 \\
\hline Irati & 836,95 & 83836 & -50.630 .000 & -25.460 .000 \\
\hline
\end{tabular}

*A estação de Major Vieira, município catarinense, teve seus dados fornecidos pela Empresa de Pesquisa Agropecuária e Extensão Rural de Santa Catarina/Centro de Informações Ambientais e de Hidrometeorologia (Epagri/Ciram).

A técnica utilizada para a interpolação do exemplo da OdF de 1972 foi a krigagem (interpolador geoestatístico), por geralmente apresentar os menores erros de interpolação. O emprego da krigagem é voltado para a representação gráfica de dados geográficos, por meio de mapas de isovalores, bem como por meio de superfícies 3D (MELLO et al., 2003; BARBOSA, 2006). O mapa foi gerado no software $\operatorname{ArcGIS}^{\circledR}$, versão 10.1 .

\section{Resultados}

Com a análise dos 50 anos de dados da estação meteorológica de Curitiba e o emprego do método de Vavrus et al. (2006) foi possível identificar inicialmente, antes da classificação das OdF, todos os limiares diários para que uma determinada temperatura média do ar pudesse ser dita como um dia frio, se caso dois dias consecutivos ou mais a temperatura média do ar estivesse igual ou menor que o limiar diário para 


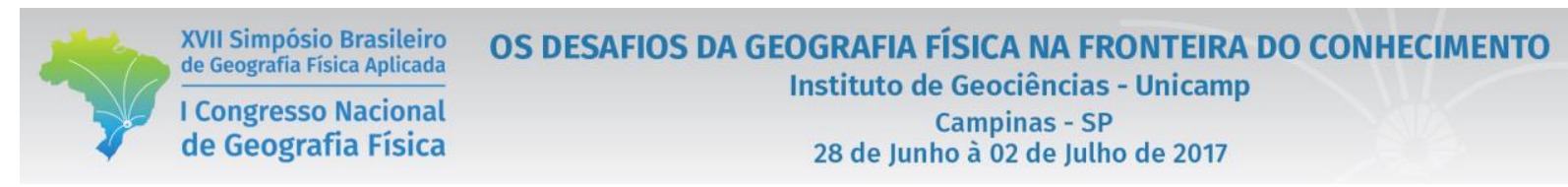

aquele peíodo era então classificada uma onda de frio. Vale ressaltar que os menores limiares descobertos foram os pertencentes aos dias invernais (junho, julho e agosto), com destaque para o dia 23 de julho, com o limiar de $6,8^{\circ} \mathrm{C}$. O limiar diário mais alto encontrado em toda análise foi o dia 25 de janeiro, onde a temperatura média diária do ar para compor um dia frio deve ser menor ou igual a $16,1^{\circ} \mathrm{C}$ (Quadro II).

Quadro II. Limiares diários $\left({ }^{\circ} \mathrm{C}\right)$ para classificação de dia frio - Curitiba/PR - 1961 a 2016.

\begin{tabular}{|c|c|c|c|c|c|c|c|c|c|c|c|c|}
\hline Dia & Jan & ev. & Iar & Abr & Mai & Jun & Jul & Ago & Set & Out & Nov & Dez \\
\hline 1 & 15,1 & 6,0 & & 13,9 & 10,6 & & & 8,7 & 9,9 & 10,3 & & 14,1 \\
\hline & 4,8 & & & & & & & & & & & \\
\hline & & & & & & & & & & & & \\
\hline 4 & &, 8 & & & & & & & & & & 14,1 \\
\hline 5 & & 6 & & & & & & & & & & \\
\hline 6 & 15,3 & 5,5 & & & & & 8,0 & & & & & \\
\hline 7 & 15,6 &, 5 & & & & & 7,8 & & & & & 14,1 \\
\hline 8 & & & & & & & & & & & & \\
\hline 9 & & & & & & & 7, & & & 1,3 & & \\
\hline 10 & & & & & & & 7, & & & & & \\
\hline 11 & & & & & & & 6 , & & & & & $t$ \\
\hline 12 & & & & & & & 7, & & & & & 4,2 \\
\hline 13 & &, 3 & & & & & 7, & & & & & \\
\hline 14 & & & & & & & 8, & & & 1,7 & 7 & 3, \\
\hline 15 & 15, & 5,4 & & & & & 8, & & & & & 14, \\
\hline 16 & & & & & & & 7, & & & & & 14, \\
\hline 17 & & 5,9 & & & & & 7, & & & 7 & & 14, \\
\hline 18 & & 5,4 & & & & & 7, & & & 3 & & 14, \\
\hline 19 & & & & & & & 7, & & & & & \\
\hline 20 & & & & & & & 7, & & & 3 & & \\
\hline 21 & 15 & & & & & & 8,0 & & & 11,2 & & \\
\hline 22 & & & & & & & 7, & & & & & \\
\hline & & & & & & & 6 & & & 9 & & \\
\hline 24 & 15 & 15,4 & & 11 & & & 7,2 & & & 12,1 & & 14,7 \\
\hline & & & & 11 & & & 7,8 & & & 12,2 & & 14, \\
\hline & 15 & & & & & & 8, & 9 & & 12 & 14 & 14, \\
\hline & & & & & & & 7, & 9 & & 12 & & \\
\hline 28 & 15 & & & & & & 8, & & & & & \\
\hline 29 & 15 & & & & & & 8, & & & & & \\
\hline 30 & 15 , & & & & & & 8, & & & 12 & & \\
\hline 31 & 16,0 & & 14,1 & & & & 8,2 & 10,0 & & 12,9 & & \\
\hline
\end{tabular}

No que diz respeito às OdF, foram encontradas no total 150 eventos, com média de três ondas por ano. Os anos de 1962, 1968, 1971 e 1987 foram aqueles com maiores registros, cada um com sete ocorrências. Os anos 1998, 2005, 2009, 2014 e 2015 não tiveram OdF registradas (Figura 2). Curitiba apresentou um elevado registro de ondas, entretanto, em comparação com o município catarinense de São Joaquim, famoso por registrar baixas temperaturas na serra, por exemplo, o número médio anual ficou abaixo, pois São Joaquim apresenta uma média de 3,5 OdF/ano (SILVEIRA, 2016). Outro dado que chama a atenção com base na Figura 2 é a linha de tendência das OdF representada ao longo dos anos, demonstrando 


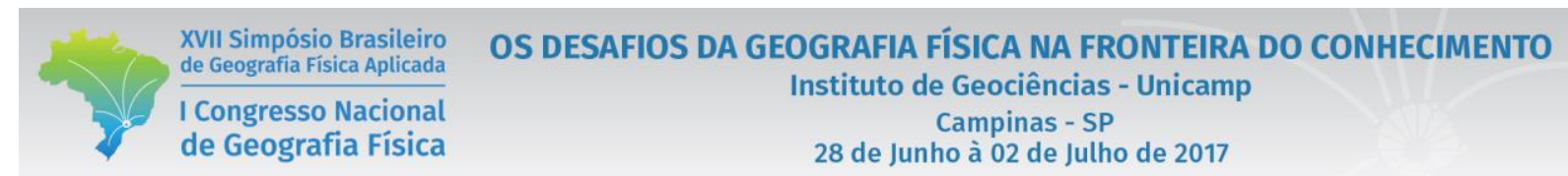

grande queda com o passar dos anos. Diante da contabilização das OdF em Curitiba, foi possível verificar que a mais duradoura foi a de agosto de 1972, com seis dias de duração, entre 29/08 e 01/09.

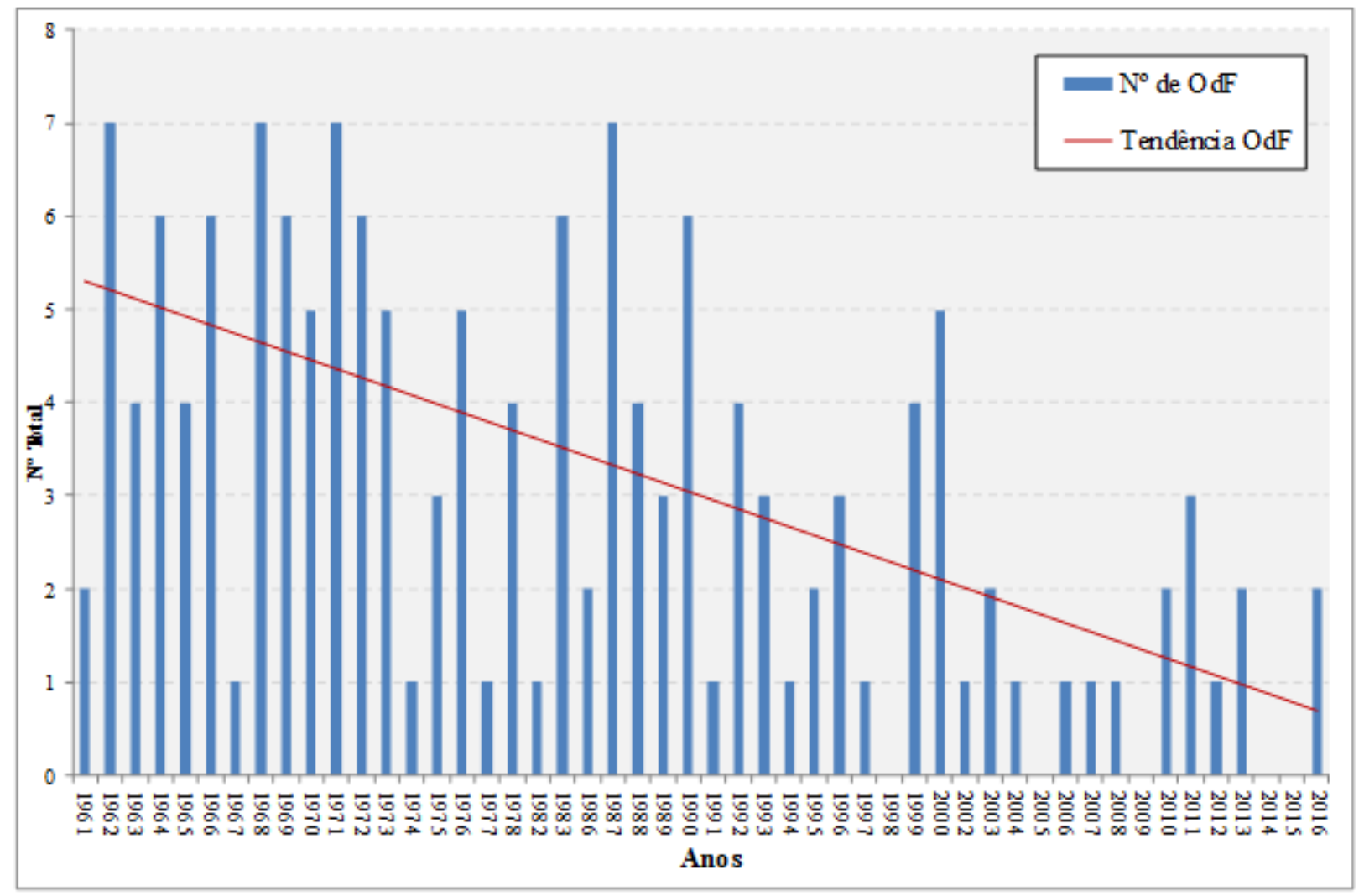

Figura 2 - Número de ocorrência de ondas de frio (OdF) por ano em Curitiba, de 1961 a 2016. Nota: os anos de 1979, 1980, 1981, 1984, 1985 e 2001 foram excluídos por apresentarem muitas falhas nos dados.

Analisando sazonalmente as OdF, notamos que os meses do inverno austral são aqueles com mais registros, com 78 ondas (52\%), enquanto a primavera representou 25,4\%, o outono 15,3\% e o verão 7,3\%. Mensalmente o mês de agosto foi o mais recorrente em OdF, com 29 durante os 50 anos contabilizados, seguido por junho (28) e julho (21). Os menores registros mensais foram em fevereiro e março, ambos com apenas um registro de OdF em todos os anos. Os episódios de onda de frio existem em todos os meses, com destaque para o inverno, posteriormente pelas estações do ano de transição, especialmente a primavera (Figura 3). Observou-se que das 150 ondas encontradas, 62,7\% foram com duração de dois dias, $28 \%$ de três dias, $4 \%$ de quatro dias, $4,7 \%$ de cinco dias e, apenas $0,6 \%$ de seis dias (uma OdF encontrada). Ressalta-se que o método de Vavrus et al. (2006) é rigoroso para classificação das ondas, mesmo assim pode fornecer grande quantidade de eventos. 

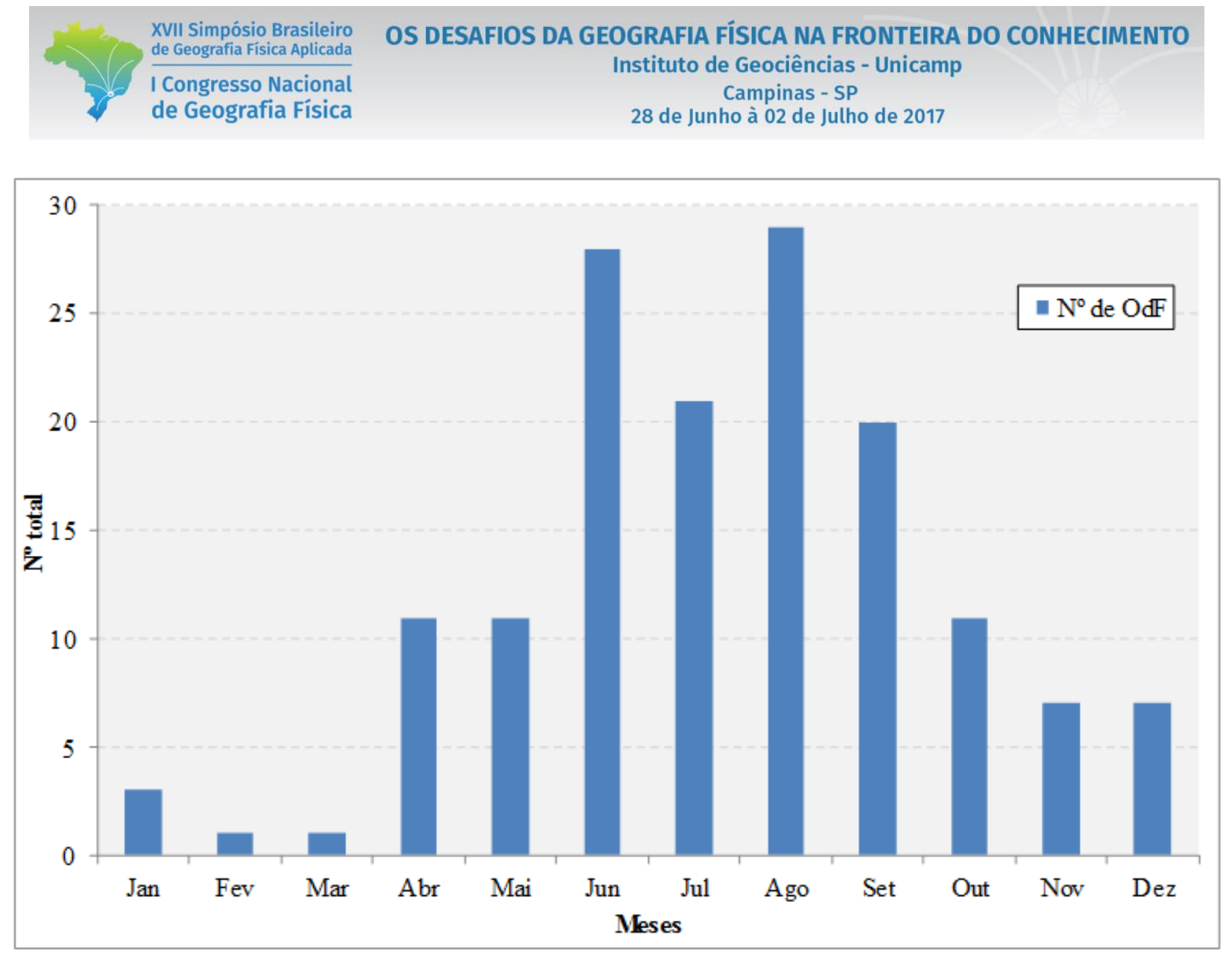

Figura 3 - Número de ondas de frio (OdF) por mês em Curitiba, de 1961 a 2016.

Titarelli (1972) publicou um artigo tratando sobre a forte onda de frio ocorrida em 1971 e sua repercussão no espaço geográfico brasileiro, mas, analisando as OdF ano a ano em Curitiba, notou-se que o ano de 1972 foi consideravelmente marcante neste sentido, pois tanto a onda mais intensa (de menor temperatura média ao longo dos dias) quanto à onda mais duradoura ocorreram neste ano, a mais intensa com média de $3,3^{\circ} \mathrm{C}$ nos quatro dias e a mais duradoura com seis dias consecutivos de duração.

Este método de classificação de onda de frio verifica os dados de temperatura média do ar especificamente na estação, todavia, a temperatura pode se expressar de forma diferente ao longo de uma cidade, variando de bairro para bairro, por exemplo, especialmente em locais mais urbanizados. Estas possbilidades de diferentes valores de temperatura no mesmo período em um único lugar podem gerar diferentes tipos de situações. Em determinada circunstância pode influenciar na diferença de enfermos internados, nos prejuizos de agricultores por culturas afetadas do mesmo município, entre outras coisas. Neste sentido, gerou-se através da técnica de interpolação, o mapa da OdF mais intensa da série histórica (08, 09, 10 e 11 de julho de 1972), conforme supracitado. 
XVII Simpósio Brasileiro de Geografia Fisica Aplicada

I Congresso Nacional de Geografia Física
OS DESAFIOS DA GEOGRAFIA FÍSICA NA FRONTEIRA DO CONHECIMENTO

Instituto de Geociências - Unicamp

Campinas - SP

28 de Junho à 02 de Julho de 2017

Para gerar a interpolação foram utilizadas outras cinco estações meterológicas (ver Quadro I), algumas não tinham todos os dias preenchidos com os dados originais, por esse motivo utilizou-se a mesma técnica de ponderação regional para preencher as falhas.

A OdF interpolada teve como média de temperatura média do ar no posto de registro em Curitiba, $3,3^{\circ} \mathrm{C} ; \mathrm{o}$ posto de Castro com $6,5^{\circ} \mathrm{C}$; Ivaí com $3,7^{\circ} \mathrm{C}$; Irati com $6,5^{\circ} \mathrm{C}$; Major Vieira em Santa Catarina registrou $3,1^{\circ} \mathrm{C}$ e; Paranaguá com $13^{\circ} \mathrm{C}$. Ressalta-se que não necessariamente nestas estações meteorológicas ocorreram OdF, as médias foram apenas verificadas tomando por base a onda contabilizada na capital paranaense. Observa-se que o território curitibano, na onda em questão, apresentou um gradiente ligeiramente maior que $0,5^{\circ} \mathrm{C}$, exatamente $0,6^{\circ} \mathrm{C}$ (Figura 4 ).

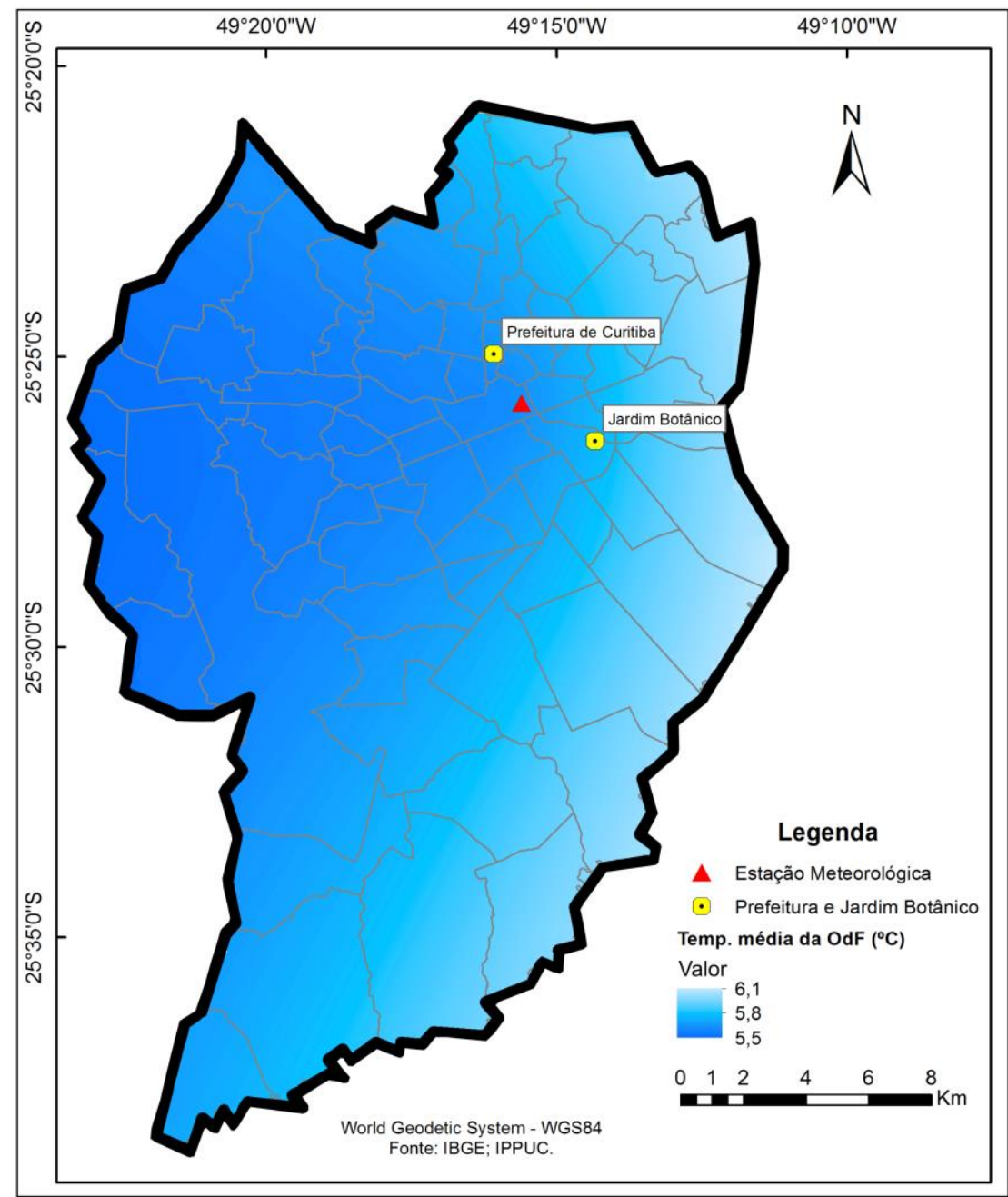

Figura 4 - OdF mais intensa dos 50 anos analisados - entre os dias 08 e 11 de julho de 1972, técnica de interpolação no município de Curitiba.

É possível notar que os setores oeste e noroeste do município foram os que registraram os menores valores de temperatura na $\mathrm{OdF}$, na casa dos $5,5^{\circ} \mathrm{C}$; enquanto os setores leste e nordeste registraram as maiores, 
com $6,1^{\circ} \mathrm{C}$, de maneira geral. Esta distribuição se explica possivelmente ao fato de que as menores temperaturas registradas nos dias da onda em questão foram nas estações a oeste e sul de Curitiba (ver Figura 1). Além disto, a única estação existente e com razoável série histórica de registros no ano de 1972, ao leste de Curitiba, foi Paranaguá, que é um município costeiro, com aproximadamente 919 metros a menos de altitude, fator importante no que diz respeito ao frio. Fritzsons et al. (2008) apontam que a temperatura no estado do Paraná pode variar diminuindo em $1^{\circ} \mathrm{C}$ entre 124 e 141 metros de ascesão vertical. Pode-se dizer que o fator altitude tem papel importante nos dados referentes a temperatura média do ar e, por conseguinte ao frio e as ondas de frio. O valor mínimo da temperatura média da OdF de 1972 analisada dentro do mapa (Figura 4) não é $3,3^{\circ} \mathrm{C}$, conforme dados observados verificados na estação meteorológica de Curitiba, pois a krigagem é um método de interpolação que calcula a distribuição do dado baseando-se nos demais postos utilizados na técnica.

\section{Conclusões}

Com base no método utilizado, observa-se que Curitiba é um município que ao longo dos anos registra um importante número de ondas de frio rigorosas, porém, nos últimos anos vem passando por diminuição nos registros em comparação com décadas anteriores. É possível afirmar que os meses invernais são aqueles com maiores registros de ondas, mesmo sendo também aqueles que apresentam limiares para classificação mais rigorosos. Mesmo com a intensidade considerável, as OdF em geral duram na maioria dois ou três dias.

Não é possível afirmar, apenas com a interpolação de uma onda, que exista um padrão de distribuição dos valores de temperatura médio das ondas dentro do território curitibano. Para isto seria necessário interpolar, da mesma forma como a onda de julho de 1972 analisada, outras ondas, com o intuito de encontrar possíveis padrões de diferença e após isto verificar o motivo para tal. Outro fator que influencia diretamente nas análises é a qualidade dos dados e as séries históricas. De forma geral não há boa qualidade nas estações vizinhas ao município de Curitiba, nas últimas décadas o número de estações meterológicas tem crescido, mas ainda não é o suficiente quando se faz necessário trabalhar com dados observados para análises pretéritas.

Análises como estas permitem conhecer mais a característica do evento, sua recorrência e até sua distribuição, podendo entender melhor seu comportamento para tomada de ações referentes ao planejamento urbano e regional. 


\section{Agradecimentos}

Os autores agradecem ao Programa de Pós-Graduação em Geografia (PPGG) e ao LabClima do Departamento de Geociências da UFSC; ao LaboClima da UFPR e; a Coordenação de Aperfeiçoamento de Pessoal de Nível Superior (Capes) pela bolsa de doutorado do primeiro autor (Processo ${ }^{\text {o: }}$ : 1696632).

\section{Bibliografia}

BARBOSA, J.P.M. Utilização de método de interpolação para análise e espacialização de dados climáticos: o SIG como ferramenta. Caminhos de Geografia, v. 9, n. 17, p. 85-96, 2006.

CARSON, C.; HAJAT, S.; ARMSTRONG, B; WILKINSON, P. Declining vulnerability to temperature-related mortality in London over the 20th century. American Journal of Epidemiology, v. 164, n. 1, p. 77-84, 2006.

CASTRO, A.L.C.; CAVALHEIROS, L.B.; CUNHA, M.I.R; BRINGEL, M.I.N.C. Manual de Desastres - Desastres Naturais. Ministério da Integração Nacional - MI, Brasília, v. 1, 2003.

COSTA, E.R.; SARTORI, M.G.B.; FANTINI, V. Estudo da relação entre El Niño - La Niña e a ocorrência de ondas de frio na região de Santa Maria - RS. Boletim Gaúcho de Geografia, v. 33, n. 1, 2007.

DANNI-OLIVEIRA, I.M. Aspectos climáticos de Curitiba, PR. Ra'ega, Curitiba, v. 3, p. 229-253, 1999.

ESCOBAR. G. Padrões sinóticos associados a ondas de frio na cidade de São Paulo. Revista Brasileira de Meteorologia, v.22, n.2, 241-254, 2007.

FIRPO, M.A.F. Climatologia das ondas de frio e calor para o Rio Grande do Sul e sua relação com o El Niño e La Niña. Dissertação (Mestrado) - Universidade Federal de Pelotas. Programa de Pós-Graduação da Faculdade de Meteorologia, Pelotas, 2008. Disponível em: <http://repositorio.ufpel.edu.br/handle/123456789/2185>. Acesso em: 12 mar. 2017.

FRITZSONS, E.; MANTOVANI, L.E.; DE AGUIAR, A.V. Relação entre altitude e temperatura: uma contribuição ao zoneamento climático no estado do Paraná. Revista de Estudos Ambientais, v. 10, n. 1, p. 49-64, 2008.

HORIKOSHI, A.S.; FISCH, G. Balanço hídrico atual e simulações para cenários climáticos futuros no município de Taubaté, SP, Brasil. Revista Ambiente e Água, v. 2, n. 2, p. 33-46, 2007.

IBGE - Instituto Brasileiro de Geografia e Estatística. Cidades: Curitiba. 2017. Disponível em: <http://www.cidades.ibge.gov.br/v3/cidades/municipio/4106902>. Acesso em: 12 mar. 2017.

IPCC - Intergovernmental Panel of Climatic Change. Summary for Policymakers. In: Climate Change 2013: The Physical Science Basis. Contribution of Working Group I to the Fifth Assessment Report of the Intergovernmental Panel on Climate Change [Stocker, T.F., D. Qin, G.-K. Plattner, M. Tignor, S.K. Allen, J. Boschung, A. Nauels, Y. Xia, V. Bex and P.M. Midgley (eds.)]. Cambridge University Press, Cambridge, United Kingdom and New York, NY, USA, 2013.

MELLO, C.D., LIMA, J.M., SILVA, A.M., MELLO, J.M.; OLIVEIRA, M.S. Krigagem e inverso do quadrado da distância para interpolação dos parâmetros da equação de chuvas intensas. Revista Brasileira de Ciência do Solo, v. 27, n. 5, p. 925-933, 2003.

MENDONÇA, F.; DANNI-OLIVEIRA, I.M. Climatologia: noções básicas e climas do Brasil. São Paulo: Oficina de Textos, 2007.

MENDONÇA, M.; ROMERO, H. Ondas de frio, índices de oscilação e impactos socioambientais das variabilidades climáticas de baixa frequência na América do Sul. Edição Especial - "Climatologia Geográfica", Revista Acta Geográfica, v.2, p.185 - 185, 2012.

MONTEIRO, M.; MENDONÇA, M. Dinâmica Atmosférica no Estado de Santa Catarina. In: Atlas de Desastres Naturais do Estado de Santa Catarina: período de 1980 a 2010, 2nd ed.; IHGSC-GCN/UFSC: Florianópolis, Brasil, v. 1, pp. 5-12, 2014.

NIMER, E. Climatologia do Brasil. Rio de Janeiro: IBGE, 422 p., 1979.

ROSSI, F.A.; KRÜGER, E.L.; BRÖDE, P. Definição de faixas de conforto e desconforto térmico para espaços abertos em Curitiba, PR, com o índice UTCI. Ambiente Construído, v. 12, n. 1, p. 41-59, 2012. 
SARTORI, M.G.B. A circulação atmosférica regional e os principais tipos de sucessão do tempo no inverno do Rio Grande do Sul. Ciência e Natura, Santa Maria, v.15, p.69-93, 1993.

SILVEIRA, R.B. Ondas de frio em São Joaquim - Santa Catarina - Brasil: a saúde como fator dependente da qualidade de vida. 2016. 172 p. Dissertação (Mestrado) - Universidade Federal de Santa Catarina, Centro de Filosofia e Ciências Humanas, Programa de Pós-Graduação em Geografia, Florianópolis, 2016. Disponível em: <http://www.bu.ufsc.br/teses/PGCN0600-D.pdf>. Acesso em: 11 mar. 2017.

TITARELLI, A.H.V. A onda de frio de abril de 1971 e sua repercussão no espaço geográfico brasileiro. Universidade de São Paulo, Instituto de Geografia, 1972.

VANHONI, F.; MENDONÇA, F. O clima do litoral do estado do Paraná. Revista Brasileira de Climatologia, v. 3, 2008.

VAVRUS, S.; WALSH, J.E.; CHAPMAN, W.L.; PORTIS, D. The behavior of extreme cold air outbreaks under greenhouse warming. Int. J. Climatol., n. 26, p. 1133-1147, 2006. 